\title{
E A FILOSOFIA: AUSÊNCIA E NECESSIDADE
}

\author{
Jefferson da Silva ${ }^{1}$ \\ Marcius Tadeu Maciel Nahur ${ }^{2}$
}

\begin{abstract}
Resumo:
O presente artigo busca refletir sobre a importância da filosofia como conhecimento humano e sua relação com as demais disciplinas humanas. Sem dirimir a importância do avanço tecnológico e das conquistas científicas, faz-se necessária a retomada da importância da filosofia, o ato de filosofar como possibilidade de crítica e fundamento para demais ciências e ainda da própria realidade. Ideias difusas sobre a importância da técnica ganham mais relevância perante as ciências humanas e sociais, pois, aparentemente, são capazes de gerarem mais lucros. No entanto, tais ideias escondem uma tentativa mascarada de impedimento da própria reflexão. Retomar a filosofia como fundamento, perpassando pelo senso comum, pela busca do conhecimento e como possibilidade de verdade, é uma tentativa de demonstrar a necessidade de uma ausência. É retomar o legado da própria condição humana, a sua capacidade de pensar e de busca por fundamentação que sustente qualquer ação metodológica.
\end{abstract}

Palavras-chave: Filosofia. Necessidade. Ausência. Multidisciplinaridade.

\section{AND THE PHILOSOPHY: ABSENCE AND NECESSITY}

\begin{abstract}
:
This article searches to reflect on the importance of philosophy as human knowledge and its relationship with other human disciplines. Without underscoring the importance of technological advancement and scientific achievements, it is necessary to resume the importance of philosophy, the act of philosophizing as a possibility of criticism and foundation for other sciences and even reality itself. Diffuse ideas about the importance of technique are more relevant to the humanities and social sciences because they are apparently capable of generating more profits. However, such ideas conceal a masked attempt to prevent reflection itself. Returning to philosophy as a ground running through common sense, the pursuit of knowledge and the possibility of truth is an attempt to demonstrate the need for an absence. It is to retake the legacy of the human condition itself, its ability to think and to search for foundation that underlies any methodological action.
\end{abstract}

Keywords: Philosophy. Necessity. Absence. Multidisciplinarity.

\section{Introdução}

O presente artigo começa com duas perguntas simples: qual a importância da filosofia como conhecimento humano? Qual sua relação com as outras formas de conhecimento? Imediatamente, parece que responder a tais perguntas não é nada complicado, principalmente, para aqueles que, de alguma maneira, têm certo interesse

1 Doutorado em Filosofia pela PUC-SP, professor do Centro Universitário Salesiano de São - Unidade Lorena e da Faculdade Canção Nova - Cachoeira Paulista/SP; E-mail: je.filos@ hotmail.com.

2 Mestre em Direito pelo Centro Universitário Salesiano de São Paulo - Unisal - Lorena/SP. Professor do Unisal (Lorena/ SP) e da Faculdade Canção Nova (Cachoeira Paulista/SP). E-mail: macielnahur@gmail.com. 
pelo conhecimento, pelo saber e pelo desenvolvimento da educação. No entanto, parece, hodiernamente, pelo menos no Brasil, que responder a essas questões nãoé tão simples assim, pois a filosofia, como outras disciplinas humanas, está perdendo seu vigor para a técnica. Parece que o estudo tecnicista é capaz de gerar mais empregos do que a própria reflexão, pois essa última seria muito etérea e nada lucrativa, própria de uma classe privilegiada que possui tempo e dinheiro para pensar e pesquisar. A impressão que se tem é que a filosofia, como outras disciplinas de base, estão perdendo o espaço da reflexão e da discussão para a tecnologia. É diante desse cenário que se torna, mais do que nunca, necessário retomar o valor das reflexões filosóficas, do filosofar.

Ela é o que pode possibilitar certa interação com as outras disciplinas, já que não é, necessariamente, egocêntrica, voltada para si mesma ou somente para utilidade, ao contrário, é excêntrica, pois ajuda a pensar o fundamento das demais disciplinas e ainda outras possibilidades que ultrapassam o imediatismo. Ela sempre vai visar ao fundamento, à busca pelas causas. Por isso, pode-se dizer que, embora esteja ausente ou quase ausente em muitas das reflexões atuais, seja nas escolas, universidades, espaço culturais, parece que é necessário atualmente, retomar a radicalidade husserliana, uma unidade universal das ciências.

Husserl partindo do radicalismo cartesiano também se propõe a buscar uma reforma completa da filosofia, cuja finalidade é desenvolver a elaa possibilidade de unidade universal das ciências. A filosofia seria a base, a fundamentação para outras ciências. Poder-se-ia aqui perguntar: Não seria pretensão de apresentar-se a filosofia comofundamento para outras ciências? Isso seria possível? Antes de responder a tal questionamento, é importante pensar que os estudos técnicos parecem ganhar mais relevância, nos dias em curso, do que as ciências humanas e sociais, pois "aparentemente" geram mais lucros do que a reflexão. No entanto, nas palavras de Heidegger, a técnica moderna, cuja finalidade é a exploração, torna-se um tanto perigosa, pois passa ser o fim dos atos humanos e não o desvelamento do ser que pode viabilizar uma vida um pouco mais autêntica para cada pessoa. Talvez, seja uma pretensão a filosofia ser fundamento para outras ciências, mas deixar de buscar respostas, tentar encontrar caminhos seja permitir que só o tecnicismo se desenvolva, e a filosofia como forma de conhecimento que se relaciona com as outras disciplinas vai ficando cada vez mais ausente. A filosofia, embora necessária, é cada vez mais ausente. O espírito crítico, embora urgente, é cada

\begin{tabular}{|l|l|l|l|l|}
\hline Qevista Dialectus & Ano 9 & n. 19 & Agosto-Dezembro 2020 & p. $114-134$ \\
\hline
\end{tabular}


vez mais ausente. Pode parecer certo ceticismo, mas parece que as universidades, faculdades estão perdendo a oportunidade de fomentar a criticidade nos alunos. Elas não estão estimulando o debate sério, capaz de mobilizar a sociedade para novos ideais, novos caminhos e novos horizontes. Um povo que não reflete, sem espírito crítico, é manipulado com enorme facilidade. Ele é moldado nas leis, nem sempre boas e justas, tornando-se facilmente manobrado pela opinião pública e pelas diversas formas de poder. Por isso, refletir a respeito da importância da filosofia, nos dias de hoje, tornou-se mais do que urgente e necessário, não obstante sua ausência.

Não se trata de uma filosofia desconectada da realidade, mas de uma filosofia concreta, capaz de ter efetividade na vida, que se encontra silenciada na sociedade da fragmentação do conhecimento. A mentalidade interdisciplinar é uma mentalidade de proprietário, que fechas as portas para qualquer outra incursão em sua parcela de saber, ainda que seja a mais diminuta. Essa mentalidade hiperdisciplinar é aquela que se contenta em saber quase tudo de quase nada. Ela padece da miopia de não enxergar nada além do seu quadrado ou, se preferir, do seu cercado.

O problema volta a ser a necessidade de se encontrar um "ponto arquimédico" ou uma mathesis magiste, o conhecimento que possibilite o entendimento da unidade para a multidisciplinaridade. Essa busca não se opera, obviamente, por meios simplistas e pragmáticos; ao contrário, ela exigirá, outra vez, sobretudo, em tempos de liquidez e relativismos, um novo esforço filosófico, até que os planos horizontais dos conhecimentos particulares e de suas específicas demonstrações sejam recolocados em alinhamento com um eixo vertical do conhecimento apodítico de uma mathesis magiste.

A metodologia desta investigação é bibliográfica, notadamente, baseada em textos de matriz filosófica. Nesse sentido, para enfrentar o problema proposto, inicialmente, é preciso retornar à questão se o entendimento da realidade pode apenas transitar do senso comum para os conhecimentos particulares, como uma espécie de gangorra, e não passar pelo nível do próprio bom senso, enquanto uma espécie de abertura de caminho para o senso crítico, capaz de propor um entendimento mais alargado, objetivo e universal da própria realidade, tal como sugere o filosofar desde os tempos imemoriais.

Em seguida, coloca-se em pauta o próprio conhecimento e a questão da verdade, quando já parecem esgotados por um mundo inundado por supostas suficientes

\begin{tabular}{|l|l|l|l|l|}
\hline Q Povista Dialectus & Ano 9 & n. 19 & Agosto-Dezembro 2020 & p. $114-134$ \\
\hline
\end{tabular}


técnicas, ciências e tecnologias. No caso, é o conhecimento filosófico que está em xeque, mas é também ele que pode dar xeque-mate a todos esses conhecimentos, quando instala a pergunta se eles são capazes de ir além de suas mais particulares realidades percebidas. No passo seguinte, traz-se à tona a reflexão sobre a importância do conhecimento filosófico e da própria filosofia, no sombrio cenário atual, em que se disseminam discursos ideológicos verticais e horizontes, vale dizer, de instituições do poder para a sociedade, e da sociedade por todas as suas redes de comunicação, de que são coisas que não servem para absolutamente nada.

Por último, então, enfrenta-se o desafio do próprio exercício de filosofar e de lançar a possibilidade de pensar uma filosofia primeira, enquanto capaz de estruturar e fundamentar as teorias das demais disciplinas e, ainda, encaminhar as práticas pedagógicas que ajudem a sociedade a se posicionar diante de conturbadas realidades antropológicas, éticas, políticas e científicas, que assustam os mais e os menos desavisados, tais como, os "fantasmas" ecológicos, econômicos e sociais, que batem às portas da humanidade nos tempos hodiernos.

\section{Do senso comum ao senso crítico}

De início, é preciso perguntar se toda e qualquer explicação da realidade tem a mesma validade. Se não tem, há de se indagar quais são os níveis de entendimento possíveis e seus respectivos significados para a existência humana.

O senso comum é uma forma de entendimento da realidade, constituído de um conjunto assistemático de opiniões e pensamentos utilizados no cotidiano das experiências corriqueiras da vida. Ele reivindica a sua validade, mas não escapa à suspeita de profunda carência de fundamento ou justificação para aquilo que afirma ou nega sobre as coisas.

Os grupos sociais, nos seus mais diversos espaços, acumulam e transferem o senso comum às suas gerações, notadamente, por meio de seus ininterruptos fazeres utilitários. Ele dá suporte ao largo espectro de atividades diárias, no âmago das sociedades, mas "sem se perguntar e sem explicar em essência o que elas significam." (LUCKESI; PASSOS, 2002, p. 36).

\begin{tabular}{|l|l|l|l|l|}
\hline Q ovista Dialectus & Ano 9 & n. 19 & Agosto - Dezembro 2020 & p. 114-134 \\
\hline
\end{tabular}


É típico do senso comum "acostumar-se a agir assim", mas ele não tem o costume de questionar "por que assim se age". Não se nega que há alguma centelha de conhecimento no senso comum, mas é também irrefutável que se trata de um modo de conhecer "superficial e fragmentário." (LUCKESI; PASSOS, 2002, p. 37).

Não podem ser esquecidos os dizeres que procuram demarcar a distinção entre o assistemático e o esforço de sistematização do conhecimento, tal como segue:

\begin{abstract}
A diferença é que o conhecimento do homem do povo foi adquirido espontaneamente, sem muita preocupação com método, com critica ou com sistematização. Ao passo que o conhecimento daquele que estudou algo foi obtido com esforço, usando-se um método, numa crítica mais pensada e uma organização mais elaborada dos conhecimentos. (LARA, 1986, p. 12).
\end{abstract}

O cerne da questão dos conhecimentos se encontra na maneira de apreensão da realidade. Nesse sentido, o saber-fazer pragmático e utilitário, quando só transita no seu próprio quadrado, corre de risco, não raras vezes, de carecer de rigoroso embasamento metodológico. Movido pelas forças das circunstâncias e das pressões imediatistas, com origem nas meras experiências comuns do cotidiano, ele permanece muito afastado da tão necessária coerência, organicidade e universalidade dos juízos cognitivos.

O senso comum não se preocupa com as inúmeras inconsistências daquilo que afirma ou nega, nem tampouco com o grau de extensão de suas proposições. Sabe apenas que, aqui e agora, ele tem sua utilidade, ainda que recheada de impropriedades não detectadas pelos seus concernidos. No fundo, o senso comum se mostra incapaz de identificar, ao menos, cinco limitações em seu raso espectro cognitivo, quais sejam, imprecisão, uso arbitrário de crendices, fragmentariedade, inconsciência e miopia utilitária. (NAGEL, 1985, p. 16).

Um passo necessário para o começo de superação do senso comum se dá pelo chamado bom senso, que pode ser definido como o conjunto de elementos de criticidade que podem e devem incidir sobre o senso comum. O bom senso já possibilita um salto qualitativo na apreensão da realidade, o que o senso comum ocupa com inegável precariedade. Assim, o bom senso pavimenta o caminho para o senso crítico, que deve ultrapassar o senso comum em metodicidade e universalidade. Não é por outra razão que se diz que o senso crítico "exige um patamar superior de investigação e produz um entendimento mais significativo e abrangente de realidade." (LUCKESI; PASSOS, 2002, p. 39-40).

\begin{tabular}{|l|l|l|l|l|}
\hline Q Povista Dialectus & Ano 9 & n. 19 & Agosto-Dezembro 2020 & p. $114-134$ \\
\hline
\end{tabular}


Na perspectiva da qualificação do conhecimento, o senso crítico tem a marca da intencionalidade e se vale de recursos lógico-metodológicos para apreender a realidade, sempre orientado pela busca da verdade. Relembrando a lógica de Abraham Lincoln, ainda ressoa no mundo atordoado pela enxurrada de informações desencontradas a seguinte advertência: 'é possível enganar todas as pessoas por algum tempo, e algumas pessoas o tempo todo, mas não é possível enganar todas as pessoas o tempo todo.' (LINCOLN apud HARARI, 2017, p. 32).

O senso crítico é um vigilante inquieto e atento para o conhecimento que persegue a realidade moldado pela verdade. E, no mínimo, é preciso levar a sério as condições de possibilidade do aparato cognitivo, que transita da sensibilidade para o entendimento e deste para a razão em relação ao objeto intuído, ao objeto conhecido e o objeto pensado, respectivamente. Para tanto, o desafio posto é que o homem saia de sua menoridade de que ele mesmo é culpado, buscando servir-se de um entendimento das coisas sem tutelas. Por isso, “[...] tem a coragem de te servires do teu próprio entendimento! Eis a palavra de ordem do iluminismo." (KANT, 1980, p. 5). Assim, é preciso se colocar a caminho, outra vez, em confronto com o desconhecido, com o mal conhecido a partir de suposições, crendices, fantasias e até hipóteses infundadas, e, ainda, com tudo aquilo que se admite já bem conhecido por meio de técnicas e instrumentos manipuladores, cada vez mais esparsos e incapazes de proposição de uma prática pedagógica fundamentada e coerente para as relações humanas e sociais nas diversas coletividades, sejam elas mais ou menos heterogêneas.

Para dar alguns passos além dessa situação aporética sobre o conhecimento da realidade, o senso crítico busca se orientar, no mínimo, em quatro direções. Primeiro, toma o objeto de investigação como parte de um todo. Segundo, examina um objeto singular como parte de algo universal. Terceiro, percebe o objeto de estudo como uma manifestação aparente de algo que não aparece, possibilidade para o ser. E, talvez a consideraçãodessa possibilidade como fundamentação precursora. Nesse sentido, o senso crítico pretende avançar em relação ao estreito horizonte de explicações eventuais da realidade, buscando conceitos universais e estruturantes da realidade-verdade.

\section{Conhecimento e verdade}

\begin{tabular}{|l|l|l|l|l|}
\hline Q Povista Dialectus & Ano 9 & n. 19 & Agosto-Dezembro 2020 & p. $114-134$ \\
\hline
\end{tabular}


Por vezes, ouve-se dizer que o conhecimento é a "elucidação da realidade." (LUCKESI, 1984, p. 47). Essa expressão comporta algumas explicitações. O vocábulo elucidar, de origem latina, é composto pelo prefixo reforçativo $e$ e pelo verbo lucere, que significa "trazer à luz". Do ponto de vista etimológico, elucidar quer dizer "trazer à luz fortemente", ou seja, "iluminar com intensidade". Desse modo, conhecer é entendido como elucidação da realidade-verdade.

A luz do elucidar, por sua vez, guarda relação direta com a incidência da "luz da inteligência" sobre essa possível realidade-verdade que se busca conhecer. Agora, trata-se de inteligibilidade. Como elucidação da possível realidade-verdade, o conhecimento é a forma de torná-la um pouco mais inteligível, transparente e clarividente.

Assim, enquanto a possível realidade-verdade, por meio de seus fenômenos, manifesta-se como opaca e enigmática, oferecendo resistências ao seu desvendamento, por parte do intelecto humano (desvendar = tirar a venda), a elucidação é a sua iluminação, o seu desvelamento (desvelar = tirar o véu). $\mathrm{O}$ ato de conhecer, portanto, como ato de elucidar, é sempre o maior esforço possível de enfrentar o desafio de desvendar-desvelar a realidade-verdade, descortinando o sentido das coisas. Essa possível realidade-verdade tanto pode ser um único objeto, como uma teoria deles formando um todo, mesmo porque nenhum objeto se apresenta isolado ao conhecimento.

No conhecimento, há quatro elementos a serem focalizados. O sujeito que conhece. O objeto a ser conhecido. $\mathrm{O}$ ato de conhecer. E, finalmente, o resultado da cognição. O sujeito opera com sua faculdade da inteligibilidade. Os conceitos advêm da apreensão adequada do mundo exterior. Desse modo, a elucidação da realidade não é ato exclusivo do sujeito, mas fruto de uma mediação interpretativa com e a partir da realidade exterior. Os fragmentos da realidade apenas lhe oferecem uma lógica de inteligibilidade, possibilitando o desvendar-desvelar, o descobrimento, de uma integração entre eles, formando-se, assim, um conceito, enquanto entendimento de totalidade e universalidade. Lembrando que o conceito não pode afastar-se do seu objeto. A propósito, a função da filosofia não é outra senão produzir conceitos.Mas, ainda é preciso considerar o ato de conhecer, tido como um processo de interação que o sujeito efetua com o objeto, sempre tentando se orientar pela lógica que possibilita expressá-lo de maneira conceitual. Então, o sujeito interage com o objeto para descobrir-lhe, na teoria e na prática, a forma de ser. No "Proêmio" ao "Comentário à Metafísica" de Aristóteles, Tomás de Aquino entende a

\begin{tabular}{|l|l|l|l|l|}
\hline Qevista Dialectus & Ano 9 & n. 19 & Agosto-Dezembro 2020 & p. $114-134$ \\
\hline
\end{tabular}


necessidade de dar atenção a uma ciência que é intelectual ao máximo edeve ser ordenadora de todas, porque é ela que versa sobre o que é mais inteligível. (AQUINATIS, 1950, p. 3). Por derradeiro, o resultado do ato de conhecer é o conceito elaborado a partir da realidade, o conhecimento propriamente dito, como algo necessário da operação intelectual capaz de embasar as mais diversas ciências que investigam parcelas da realidade. Não é por outra razão que assim se diz sobre o pensar filosófico:

O filósofo é bom em conceitos, e em falta de conceitos, ele sabe quais são inviáveis, arbitrários ou inconsistentes, não resistem um instante, e quais, ao contrário, são bem feitos e testemunham uma criação, mesmo se inquietante ou perigosa. (DELEUZE; GUATTARI, 2010, p. 10).

O conhecimento existe para a contenção de tudo quanto possa haver de enganoso ou falso sobre a possível realidade-verdade. Não é demais ressaltar que, em tempos de declínio da razão, e de ascensão dos emotivismos, sensacionalismos e militâncias apelativas sobre as coisas, a "ignorância está na moda.” (KAKUTANI, 2018, p. 39). O conhecimento, como elucidação da realidade-verdade, decorre de um esforço concentrado de investigação metódica para se descobrir aquilo que se oculta, se escamoteia ou se manipula, ficando distante de algo que possa ser entendido razoavelmente, e, além disso, muito longe do que deva ser bem entendido pela racionalidade objetiva e universal. Só depois de elucidado em sua possibilidade de ser é que um objeto intuído, conhecido ou pensado pode ser considerado minimamente entendido.

O conhecimento proporciona ao sujeito condições de entender a possível realidade-verdade e melhor conviver com ela, tornando-a adaptada às suas necessidades. O conhecimento crítico é, pois, um indispensável fator de libertação, inclusive, das informações desqualificadas e das opiniões rasas, que vociferam suas "verdades" pelos arredores do mundo, sobretudo, valendo-se das redes sociais. É esse cenário assustador que faz lembrar os dizeres agudos a seguir declinados:

As redes sociais deram o direito à palavra a legiões de imbecis que, antes, só falavam nos bares, após um copo de vinho e não causavam nenhum mal à coletividade (...). Nós os fazíamos calar imediatamente, enquanto hoje eles têm o mesmo direito de palavra do que um prêmio Nobel. [...] O drama da internet é que ela promoveu o idiota da aldeia aportador da verdade. [...] É a invasão dos imbecis. (ECO, 2017).

\begin{tabular}{|l|l|l|l|l|}
\hline Q Povista Dialectus & Ano 9 & n. 19 & Agosto-Dezembro 2020 & p. 114-134 \\
\hline
\end{tabular}


As palavras de Umberto Eco, agudas sobre esse universo das tecnologias da informação e da comunicação, fazem ecoar as críticas de Heidegger à técnica: “A filosofia não é um saber, que, à maneira de conhecimentos técnicos e mecânicos se possa aprender diretamente ou, como uma doutrina econômica e formação profissional, se possa aplicar imediatamente e avaliar de acordo com sua utilidade." (HEIDEGGER, 1966, p. 45).

Eventuais mais erros do que acertos não são indicadores de derrocada da razão filosófica; ao contrário, constituem uma forma de entendimento coerente, que não deixa de considerar condições e limitações com sensatez. Porém, se os acertos atestam a inteligibilidade da possível realidade-verdade, os erros levam a movimentar o conhecimento para desfazê-los, tendo sempre à frente o horizonte da realidade-verdade a ser desvendada-desvelada. E esse conhecimento persistente não é outro senão o filosófico e a próprio ato de filosofar, enquanto busca incessante do saber, por saber que não sabe, aliás, o que com muita dificuldade sabe.

\section{Conhecimento filosófico e filosofia}

Um primeiro ponto básico quando se fala em conhecimento filosófico e da própria filosofia é não deixar passar ao largo a discussão sobre sua importância, sobretudo, quando se disseminam discursos ideológicos verticais e horizontes, vale dizer, de instituições do poder para a sociedade, e da sociedade por todas as suas redes de comunicação, de que essas são coisas que não servem para absolutamente nada. Não se questiona, nos tempos atuais, a importância das técnicas, das ciências e das tecnologias. Entretanto, no tocante ao conhecimento filosófico e à própria filosofia, nesses dias, volta e meia se lança aqui e ali o questionamento sobre sua real necessidade, isso quando já não se coloca logo o rótulo de que não fazem o menor sentido, sem o mínimo incomodo com sua ausência.

Sem fechar o círculo, não é tão difícil detectar, ao menos, cinco atitudes em relação ao conhecimento filosófico e à filosofia, não surpreendendo que as negativas se sobressaem como maioria. Para uma primeira atitude, conhecimento filosófico e filosofia são coisas inúteis, produtos de mentes diletantes e sem qualquer comprometimento com os problemas cotidianos reais das pessoas. Assim consideram todos aqueles que veem o conhecimento filosófico e a filosofia como construtores de castelos estéreis de ideias e

\begin{tabular}{|l|l|l|l|l|}
\hline Q Rovista Dialectus & Ano 9 & n. 19 & Agosto-Dezembro 2020 & p. $114-134$ \\
\hline
\end{tabular}


conceitos que servem apenas para preenchimento de tempo de um grupo que pode ser rotulado de "fora da realidade e que não tem nada de mais importante para fazer".

Uma segunda atitude, realizando uma espécie de jogo duplo, fala do conhecimento filosófico e da filosofia com certa polidez e até de forma elogiosa, mas não leva a sério o que diz, porque, no fundo, considera o conhecimento filosófico e a filosofia excrescências para a sociedade que precisa de vida produtiva.

Uma terceira atitude, mais especificamente, segue na direção de uma blague. Uma frase já folclórica expressa bem essa visão, a saber: com ou sem conhecimento filosófico e filosofia, o mundo segue tal e qual, de modo que não trazem qualquer orientação concreta sobre de onde ele vem e para onde vai.

Uma quarta atitude, assumida até por poderes constituídos, entende que conhecimento filosófico e filosofia são "perigosas armas em mãos erradas", vale dizer, das pessoas, dos cidadãos, motivo pelo qual são desqualificados, aqui e acolá, pelos detentores do mando.

Obviamente, todas essas quatro atitudes são negativas em relação ao conhecimento filosófico e à filosofia, ainda que camuflem, algumas vezes, o jogo apenas estratégico de dizer que o conhecimento filosófico e a filosofia até poderiam ser valorizados se a realidade da vida fosse outra, ou seja, se outras prioridades econômicas e sociais da coletividadejá tivessem sido satisfeitas. Em poucas palavras, primeiro viver e, se sobrar tempo, então, talvez, até seja interessante dar uma flertada com o pensar filosófico, mas não muito para "não ficar com a cabeça nas nuvens e perder contato com o chão". Nesse cenário de negatividades, resta uma quinta atitude, única de caráter positivo, que assume o conhecimento filosófico e a filosofia em seu aspecto essencial de ser uma forma de entendimento necessário à "práxis" humana, rejeitando as visões distorcidas sobre sua real importância para a vida em todas as suas dimensões. Nesse sentido, atenção seja dada aos seguintes dizeres:

Devemos repelir qualquer ideia de que a filosofia seja um quadro exposto à contemplação do homem, ou mesmo um entorpecente para mergulhá-lo em doces sonhos etéreos, enquanto esquece a realidade da vida e o mundo que há a fazer dentro dela. A filosofia é, antes de mais nada, em primeiro lugar, e acima de tudo, [...], uma ferramenta, um instrumento de açãocom a ajuda da qual o homem conhece a natureza e busca o conforto físico e espiritual para a vida. Se o homem realmente se destaca dos outros animais pela amplidão e profundidade de seu pensamento, se tudo o que ele realizou, desde que, saindo da selvageria, começou a construir o que chamamos de civilização, foi a concretização desse pensamento que, evoluindo, se transformou, através do tempo e do espaço. Não há dúvida de que esse pensamento, mobilizando os

\begin{tabular}{|l|l|l|l|l|}
\hline Qonista Dialectus & Ano 9 & n. 19 & Agosto-Dezembro 2020 & p. 114-134
\end{tabular}


dedos de sua mão, é sua principal arma na conquista da natureza e, portanto, de sua liberdade. (BASBAUM, 1978, p. 302-303).

Assim, a verdadeira compreensão do significado do conhecimento filosófico e a filosofiaimplica assumir como formas de entendimento da realidade que ajudem melhor orientar o ser humano para sua ação individual e social com os diversos mundos com os quais ele interage diuturnamente. Ela pode e deve contribuir para que ele não se deixe cegar por todo tipo de estratégias manipuladoras, que vão de ditaduras de opiniões pré-configuradas a torrentes de informações desencontradas e desqualificadas, que lhe afastem de procurar o sentido do próprio existir humano com todos os desafios próprios de cada tempo.

Desde que se recusem visões pré-concebidas, explícitas ou implícitas, sobre o conhecimento filosófico e a filosofia, de modo a diminuir ou alijar a real importância que possuem de fato, então, pode-se avançar para um entendimento um pouco mais elaborado sobre o pensamento filosófico, tal como exposto nas palavras a seguir:

Seja a filosofia o que for, está presente em nosso mundo e a ele necessariamente se refere. Certo é que ela rompe os quadros do mundo para lançar-se no infinito. Mas retorna ao finito para, aí, encontrar seu fundamento histórico sempre original. Certo é que tende aos horizontes mais remotos, horizontes situados para além do mundo, a fim de ali conseguir, no eterno, a experiência do presente. Contudo, nem a mais profunda meditação terá sentido se não relacionar à existência do homem aqui e agora. A filosofia entrevê os critérios últimos, a abóbada celeste das possibilidades, e procura, à luz do aparentemente impossível, a via pela qual o homem poderá enobrecer-se em sua existência empírica. (JASPERS, 1976, p. 138).

O filósofo procura mostrar que a filosofia é uma forma de entender a cotidianidade do mundo com suas grandezas e suas misérias. Mas, essencialmente, ela é o caminho pelo qual é possível enobrecer a própria existência. Mesmo que a filosofia elabore conceitos tão abstratos, no fundo, eles nada mais fazem do que expressar a vida de forma refletida. Eles brotam da realidade e, para abarcá-la na sua universalidade, precisam ultrapassá-la, propondo entendimentos que se universalizem e sejam fundamentos mais sólidos para vários tipos de ações, especialmente, as pedagógicoeducativas. A propósito, é que se pode captar nas anotações aqui trazidas:

[...] a filosofia reflete sobre os dados concretos do dia-a-dia; porém, para cumprir seu papel, necessita descolar-se dessa realidade empírica para, no

\begin{tabular}{|c|c|c|c|}
\hline Rovista Dialectus & Ano 9 & n. 19 & Agosto - Dezembro 2020 \\
\hline
\end{tabular}


nível do pensado, deslindá-la e, assim, possibilita ao ser humano uma orientação para asua prática. Desse modo, e tão-somente desse modo, é que a filosofia pode ser significativa para o ser humano, individual ou coletivo. Pensando o concreto, ela constitui um entendimento coerente e crítico que possibilita o direcionamento da prática cotidiana. (LUCKESI; PASSOS, 2002, p. 82-83).

A filosofia não constitui, de modo algum, uma simples abstração independente da vida. Evidentemente, o ser humano não se alimenta de filosofia, mas, sem dúvida alguma, sua existência se amesquinha, chega à inanição, sem a ajuda dela.A filosofia pode lhe proporcionar uma forma um pouco mais consciente e crítica de pensar, agir e sentir tudo aquilo que a existência lhe reserva no inevitável pêndulo das acomodações e inquietações. De uma vez por todas, é preciso não negligenciar a atenção a essa íntima ligação entre o que parece mais abstrato e o que se apresenta de mais concreto, tal como se pode perceber nessas palavras a seguir: "A filosofia vazada na linguagem conceitual é profundamente solidária com a vida, com a existência. Ela marca o desejo, a ânsia que o homem tem de elucidar a sua circunstância existencial." (BUZZI, 1973, p. 9).

Não há como viver sem se perguntar sobre o real sentido das coisas. Não há como colocar algo em prática sem se questionar sobre o seu significado e seu impacto na vida. As práticas educativas, os mecanismos de ensino e pesquisa institucionais, com suas tecnologias ativas, não podem ir muito longe se carecem de fundamentos filosóficos mais sólidos que ofereçam possibilidades reais de tirar as pessoas de suas "cavernas solipsistas", quando elas se inclinam a fazer proposições teóricas e práticas sobre as realidades éticas, políticas, científicas, econômicas, sociais, culturais, religiosas e ambientais de um mundo complexo e em profundas e aceleradas transformações. A respeito dessa visão sobre a filosofia, não seria um despautério se ter uma clara compreensão do que ela pode operar no mundo, tal como se vê:

A filosofia é a resposta que uma sociedade traz à dupla exigência de refletir criticamente e de se explicar teoricamente quanto aos valores e representações que tornam inteligíveis, ou pelo menos aceitáveis, para os indivíduos que nela vivem um modo de ser, isto é, um modo de viver e de morrer, de imaginar e de conhecer, de amar e de trabalhar, de mandar e de obedecer etc., que constitui o legado da tradição, e que os indivíduos devem assumir e, de fato, já assumiram antes mesmo de poder responder por ele, ou justificá-lo diante da própria razão. (LIMA VAZ, 1978, p. 7).

\begin{tabular}{|l|l|l|l|l|}
\hline Q Povista Dialectus & Ano 9 & n. 19 & Agosto-Dezembro 2020 & p. 114-134 \\
\hline
\end{tabular}


O que se quer dizer é que a filosofia busca tratar dos fundamentos últimos que ajudam a dar sentido ao existir humano na história. A filosofia se encarrega de fundamentar a concretização de um espírito e de um conceito, tentando demonstrar-lhe alguma verdade objetiva e universal, além de influenciar e orientar o curso da história dos propagadores de tais ideias. Dessa maneira, a filosofia não se reduz apenas à interpretação do "já vivido" e do que se "está vivendo", mas também o entendimento das aspirações maiores da humanidade. Nesse sentido, ela é o sustentáculo de um modo de viver de agora em diante. No entanto, não se vai adiante sem um referencial marcante, um fundamento matricial, que oriente esse horizonte. Assim, no mundo atual, tão contaminado de visões idiossincráticas e exclusivistas, enredado por apelos imagéticos e cliques apressados em aparelhos de ininterrupta conexão, inundando todos os espaços da vida, desde os lares até os ambientes escolares, com informações superficiais e desorientadas sobre as coisas do mundo, é mais do que urgente e necessário voltar ao filosofar e, se possível, a uma filosofia primeira, diante de tanta ausência de um pensamento mais crítico, coerente e consistente a respeito da realidade-verdade.

\section{Filosofar e filosofia primeira}

O exercício do filosofar implica que o próprio ser humano, individual e coletivamente, o quanto lhe seja possível, assuma a sua existência e se comprometa a lhe dar sentido crítico e consciente em suas ações.

A raiz da filosofia é, precisamente, o espantar-se, o maravilhar-se, surgido no ser humano ao se defrontar com a totalidade e universalidade das coisas. A atual era das técnicas, ciências e tecnologias, com seus artefatos de informação e comunicação por todos os lados, traz muitos desafios quanto aos seus fins, sobretudo, em relação às práticas pedagógico-educativas. Mas, entre todos os desafios, o principal deles parece ser a questão de um pensamento organizado que seja fundamento estruturante ou, então, condição de possibilidade de entendimento dessa realidade. Não é por outro motivo que se colocam as seguintes anotações:

Em suma, qual a atitude do homem diante do quadro oferecido pela evolução tecnológica até agora? Como poderá ele ter uma visão menos fragmentada do processo, através de novos saberes ou conjunto de saberes, nem sequer cogitados até agora? (MORAIS, 1971, p. 5-6).

\begin{tabular}{|l|l|l|l|l|}
\hline Q Povista Dialectus & Ano 9 & n. 19 & Agosto-Dezembro 2020 & p. 114-134 \\
\hline
\end{tabular}


As respostas a esses questionamentos devem ser vasculhados no universo filosófico. A filosofia, já em seus primórdios, não era uma mera atividade lúdica, mas a busca de um saber epistêmico, especulativo, teórico, capaz de levar o ser humano ao conhecimento das primeiras e últimas causas de todas as coisas. Não se pode confundir a filosofia com os sabores emotivistas de tudo quanto seja sem-razão. O filosofar autêntico sempre buscou juízos apodíticos da razão, ou seja, necessários e suficientes para fundamentar os conhecimentos das coisas em suas múltiplas realidades. O saber filosófico, desde seus primeiros passos, persegue princípios e fins últimos da realidade. Nessa busca, o saber filosófico não finca raízes no setorial. Ela sai à procura do englobante em todos os campos da atividade epistêmica humana. Suas proposições devem ser válidas para todas as esferas e regiões do saber humano. Nesse sentido, é preciso não perder de vista essas palavras de orientação sobre a relevância inafastável do saber filosófico:

\footnotetext{
Ao estabelecerem-se leis e princípios, devem estes ter validez em todos os campos do conhecimento, porque só assim se constituirá o nexo que estrutura o saber epistêmico num conjunto coordenado, [...], que é a adequação dos opostos analogados, cujas funções subsidiárias estão subordinadas à função principal, cuja norma é dada pela totalidade. (SANTOS, 2009, p. 51).
}

As sociedades contemporâneas, em geral, não manifestam preocupação filosófica, seja com uma filosofia primeira estruturante ou mesmo com uma filosofia como condição de possibilidade de entendimento da realidade. Ao menos uma ou outra deveriam ser retomadas para fundamentação. $\mathrm{O}$ equívoco seria não considerar nenhuma delas como essa fundamentação para os conhecimentos que investigam, em suas respectivas áreas, a própria realidade.

A filosofia primeira estruturante será tratada aqui como "filosofia concreta". Atenção seja dada ao adjetivo "concreta". Não está empregado em sentido comum, mas no sentido original do latim cum crescior, vale dizer, "crescer junto". Desse modo, só se cresce junto em movimento. É urgente movimentar o saber filosófico. Uma filosofia concreta, portanto, cresce junta com alguma outra coisa. Qual coisa seria essa, caberia perguntar. A resposta não poderia ser outra, senão a seguinte: “A rigor, todas as aplicações do pensamento humano, das quais a filosofia é fundamento e garantia." (SANTOS, 2009, p. 27). Desse modo, uma filosofia concreta é aquela que examina os princípios de todas

\begin{tabular}{|l|l|l|l|l|}
\hline Qevista Dialectus & Ano 9 & n. 19 & Agosto-Dezembro 2020 & p. $114-134$ \\
\hline
\end{tabular}


as outras formações de conhecimento humano ao mesmo tempo em que espia a si mesma como elemento de garantia da validade desses princípios. Nesse movimento, ele transforma não somente a área que tocou, mas também a si mesma, trazendo junto os elementos dessa área em uma síntese dos conhecimentos humanos em um novo patamar de saberes. A lógica da filosofia concreta é inclusiva, e não excludente, no ato de "crescer com" os conhecimentos específicos. Ela é o elemento abstrato que tem como objetivo prover de argumentos universais e válidos as possibilidades de entendimento de todas as demais regiões do conhecimento. Mário Ferreira dos Santos colocou em prática uma "filosofia concreta". Em uma palestra, ao ser indagado do porquê de sua obra tratar de temas distintos e distantes como economia, linguística e psicologia, se ele era filósofo, a sua resposta foi surpreendente. Sua explicação inverteu os termos da questão: justamente por ser filósofo sua missão é examinar os fundamentos epistemológicos de todas as searas do saber; uma filosofia incapaz de realizar esse exame não é uma filosofia concreta, mas somente um conjunto doutrinário (SÁ MARTINO, 2009, p. 28). Ao que tudo indica, a inspiração disso é tomasiana, quando o escolástico assim se pronunciava: oconhecimento dos fundamentos de uma ciência não podem existir nessa ciência em si, mas devem ser pensados a partir de fora, com uma ciência cujos princípios já não precisem e nem comportem uma demonstração. (AQUINAS, 1968, p. 35-37). Essa ciência do fundamento não demonstrável é a filosofia primeira ("metafísica"), ou seja, a ciência da mais alta forma do Ser. E o que é ele, seria importante perguntar. A resposta é simples: "O ser é o que dura, o que afirma, o que perdura, o que fundamenta tudo quanto é sendo para os modernos. É o fundamento de todo ente.” (SANTOS, 2009, p. 81). Isso significa que o real é inteligível na medida em que se torna estruturado conceitualmente.

Entretanto, há ainda proposta de desconstrução dessa filosofia primeira (“metafísica"), por ser considerada de totalidade rígida, de tal modo que se apregoa que, na contemporaneidade, a sua tarefa, agora, é "articular um conceito de ente que é condição de possibilidade de todas as outras afirmações sobre as entidades, e não apenas sobre as entidades atuais, mas também sobre as puramente possíveis." (OLIVEIRA, 2014, p. 15).

Heidegger foi o pensador que alterou, de modo radical, a reviravolta moderna da dimensão do ente para a do sujeito, além de dizer que a linguagem humana pode falar dos entes, mas não do ser. O desvelamento do ser não pode ser obra de um ente, mesmo que privilegiado como o ser-aí, mas só pode se dar através da iniciativa do

\begin{tabular}{|l|l|l|l|l|}
\hline Qevista Dialectus & Ano 9 & n. 19 & Agosto-Dezembro 2020 & p. $114-134$ \\
\hline
\end{tabular}


próprio ser. Aqui se encontra a reviravolta do pensamento hideggeriano, a saber: o homem não pode desvelar o sentido do Ser. A metafísica não tem feito outra coisa senãofocalizar apenas os entes, e não o Ser. Para ele, então, é preciso indagar pelo Ser, trazer à luz esse esquecido. (HEIDEGGER, 1966, p. 17). De qualquer modo, através de suas intuições, ele acabou abrindo caminho para a rearticulação da metafísica, vale dizer, para uma "metafísica primordial”, que assim é definida:

\begin{abstract}
A tese central neste ensaio é, porém, que há mais para metafísica do que metafísica geral e especial, ou ontologia geral e especial, como já caracterizado. Metafísica também inclui uma mais profunda ou mais fundamental teoria que pode ser chamada de metafísica primeira - metafísica primária - ou, mais adequadamente, [...] - metafísica primordial. (PUNTEL, 2011, p. 304-305).
\end{abstract}

Entretanto, articular uma teoria metafísica completa significa elabora um catálogo completo das categorias sob as quais todas as coisas e suas relações mútuas podem se enquadrar. Essa elaboração levaria à distinção entre categorias básicas e categorias derivadas. Mais ainda. Isso exigiria uma especificação sobre como entidades derivadas podem ser analisadas em termos de entidades das categorias básicas. Com se diz, nesse ponto "precisamente, consistiria na tarefa de fornecer uma explicação de tudo o que há. Certamente não muitos metafísicos hoje estariam em condições de oferecer uma teoria completa de categorias." (OLIVEIRA, 2014, p. 40).

Quando o problema parece desatado, na realidade, ele não está ainda bem resolvido. A história do pensamento metafísico mostrou que persistem dificuldades quando se reduz a metafísica à busca dessas categorias mais gerais, Não se trata apenas de discordâncias quanto às categorias, mas também divergências com relação aos objetos que há no mundo. A pergunta sobre que objetos ou coisas há no mundo precede a indagação sobre as categorias. Contudo, essas dificuldades não levam, necessariamente, ao descarte de uma metafísica sistemática no mundo contemporâneo. E, os debates metafísicos mais recentes, seguem ainda apontado para certas exigências inafastáveis dessa metafísica na quadra atual, não deixando de assinalar alguns pontos basilares: ela tem de ser fundamentada em argumentos transcendentais; tem de fazer jus ao fato moral; tem de fazer jus à realidade como ela se manifesta, o que não implica, necessariamente, um processo indutivo; nela deve haver um espaço próprio para a análise da interioridade;

\begin{tabular}{|l|l|l|l|l|}
\hline Qevista Dialectus & Ano 9 & n. 19 & Agosto-Dezembro 2020 & p. $114-134$ \\
\hline
\end{tabular}


e, uma boa metafísica tem de conter uma ontologia da intersubjetividade e do social. (HÖSLE apud OLIVEIRA, 2014, p. 41).

A tese básica é a de que há múltiplos seres. É aqui que se fala, então, de uma ontologia achatada, capaz de articular um ideal que poderia ser assimilado por diferentes posições metafísicas. Não se trata de ecletismo, mas daquilo que pode ser chamado de pequena ontologia. Ricouer pode ajudar nessa questão. Em "História e Verdade", ele sustenta que afirmar o ser é importante, mas não é de menor relevância negar. O mérito das filosofias negativas foi colocar em xeque a concepção essencialista de muitas coisas. Não deixa de ser curiosa a retomada que Ricouer faz de Platão, apontando-o como o primeiro a reconhecer que "o ser e o não-ser nos embaraçam.” (PLATÃO apud RICOUER, 1968, p.337). Esse embaraço torna-se, outra vez, canteiro fértil para que se devolva à sociedade contemporânea, o filosofar entre essas duas possibilidades, uma necessidade diante da ausência do pensar filosófico nessas miríades de informações e conhecimentos técnicos, científicos e tecnológicos que enredaramnão só o mundo a fora, mas também toda a cadeia de ensino, da educação básica aos cursos superiores. É a partir daí que a academia pode ser, com seu espaço de acolhimento das pluralidades e das diversidades, promotora do ato de filosofar capaz colocar as pessoas à procura de fundamentos para seus conhecimentos, formados desde o senso comum até os mais especializados.

\section{Conclusão}

Parece uma pretensão daquele que se preocupa com o ato filosofar a afirmação de que a filosofia deveria voltar, no que é possível, à sua vocação originária, ser fundamento para demais disciplinas, pois posta ao lado das outras disciplinas ela realmente parece perder sua validade, pois voltando-se para o um ambiente em que a preocupação econômica parece o métie (assunto) do momento, a filosofia vista sob este aspecto torna-se realmente inútil, no entanto, posta como possibilidade de fundamento e de criticidade das disciplinas e do sistema econômico, ela ainda continua tendo seu valor irrevogável.

O filósofo com sua capacidade de conceituação, sua contenção quanto ao duvidoso, o enganoso e o falseamento, ainda continua capaz de ouvir, ler, criticar e

\begin{tabular}{|l|l|l|l|l|}
\hline Qevista Dialectus & Ano 9 & n. 19 & Agosto-Dezembro 2020 & p. $114-134$ \\
\hline
\end{tabular}


embasar as mais diversas ciências que investigam a realidade. E ainda, embora possa parecer uma pretensão, ele é capaz de vislumbrar o horizonte que articula ou desarticula o real-social. Partindo da própria realidade e das discussões tão difundidas e difusas sejam políticas, ecológicas, religiosas, econômicas e outras, a filosofia pelo esforço e operação intelectual é capaz elaborar conceitos críticos e ainda delimitá-los para avanço da própria ciência evitando assim, a superficialidade e anomalias, tanto nas práticas científicas quanto na relatividade das ações. Ela pela sua reflexividade e pelo seu esforço de investigação metodológica continua vigorosa em descobrir o que se oculta, se escamoteia e se manipula nos discursos, narrativas e nas práticas ambíguas. Ainda que um horizonte esteja distante a filosofia pelo seu próprio ato de filosofar é capaz de enxergar as arestas necessárias a serem enfrentadas. No entanto, como se afirmou-se ao longo do artigo, ideias difundidas um tanto negativas rodeiam seu horizontes ou corroboram para sua ausência a fim de torná-la mais ausente como, conhecimento inútil, produto de mentes diletantes, conceitos abstratos e conhecimento improdutivo. Tais ideias podem estar camuflando uma tentativa defensiva e perversa de manter a reflexão e a crítica afastadas, impondo à massa opiniões arbitrárias como se fossem parte da própria realidade.

Por isso, assumir o ato de filosofar ou retomar o tema da filosofia como necessidade embora ausente é mostrar a importância e ao mesmo tempo estimular aquilo que é próprio de cada ser humano a capacidade de reflexividade. Mais do que nunca parece ser necessária a retomada do filosofar, essa capacidade propriamente humana de refletir e tentar encontrar fundamento para ação e para realidade. É conclamar os filhos da terra a sair na menoridade e avançar para uma maioridade através da crítica não para aliar-se a um partido ou a um posicionamento ideológico, mas uma tentativa asceta de interpretar, buscar e fundamentar a própria morada. Basear-se somente no fazer, nas técnicas, na produtividade como começo, meio e fim, é caminhar para o próprio abismo, pois como esse saber fazer poderá se manter sem motivações pungentes que fundamentem seu próprio existir. Pode-se dizer que com o tempo essas técnicas entrarão em inanição sem alcançar o que se propôs, o crescimento. Sem a reflexão e sem a busca de fundamentação tudo pode ser tornar massa de manobra. Essa busca de fundamentação, que não pode ser desconsiderada nem no universo teórico, nem no plano prático, evoca uma nova investigação metafísica. Não é tão simples dizer que se trata desta ou daquela metafísica que o pensamento filosófico já percorreu. Isso seria fechamento em um modelo

\begin{tabular}{|l|l|l|l|l|}
\hline Q Povista Dialectus & Ano 9 & n. 19 & Agosto-Dezembro 2020 & p. $114-134$ \\
\hline
\end{tabular}


previamente estabelecido. O momento atual de complexidades cognitivas exige aberturas epistêmicas. Mas, de qualquer modo, esse processo de escavação de um horizonte mais profundo remete a se pensar a possibilidade estruturante de uma metafísica que talvez possa retomar uma fundamentação ao estilo dos argumentos transcendentais, com conexões com as múltiplas realidades existenciais, contendo ainda uma ontologia bem de perto das manifestações intersubjetivas, não só no nível das relações sociais, mas também na dimensão da formação integral do ser humano.

Por isso, refletir e retomar o ato de filosofar é uma tentativa constante de entender a realidade e na medida do possível orientar o ser humano na sua ação individual e social. Longe de ser uma espécie de conhecimento consolador para ação humana, uma certa terapia ou qualquer tipo de autoajuda, o ato de filosofar impede que estratégias manipuladoras sejam de ideias pré-configuradas ou de informações desencontradas tomem corpo assumindo uma posição de verdade para as pessoas. Por isso, mais do que nunca, embora pareça que a filosofia como fundamento esteja tão ausente, ela se faz necessária para a fomentação da reflexão, para o impedimento de manipulação das massas, para o avanço das disciplinas e demais práticas pedagógicas. Ela aliada as outras disciplinas é capaz de gerar um ponto de unidade realizando a efetivação da multidisciplinaridade tão necessária para os conhecimentos produzidos, produtivos, mas espaçados e separados.

\section{Referências}

AQUINATIS, Thomae. Duodecim libros Metaphysicorum Aristotelis Expositio. In: Proemium. Turim:Cathala-Spiazzi, 1950.

AQUINAS, Thomas. Comentary on Aristotle's Physisc. London: Routledge, 1968.

BASBAUM, Leôncio. Sociologia do materialismo. São Paulo: Símbolo, 1978.

BUZZI, Arcângelo. Introdução ao Pensar. Petrópolis: Vozes, 1973.

DELEUZE, Gilles; GUATTARI, Félix. O que é a filosofia? Trad. de Bento Prado Jr. e Alberto Alonso Muñoz. 3. ed. São Paulo: Editora 34, 2010.

ECO, Umberto. Umberto Eco - Internet, Social Media e Giornalismo. Disponível em: https://www,youtube.com/watch?v=u10X-GPuO3C4. Acesso em 31 ago. 2019.

\begin{tabular}{|l|l|l|l|l|}
\hline Q Povista Dialectus & Ano 9 & n. 19 & Agosto-Dezembro 2020 & p. $114-134$ \\
\hline
\end{tabular}


HARARI, Yuval Noah. 21 lições para o século 21. Trad. de Paulo Geiger. São Paulo: Companhia das Letras. 2018.

HEIDEGGER, Martin. Introdução à Metafísica. Trad. de Emmanuel Carneiro Leão. Rio de Janeiro: Tempo Brasileiro, 1966.

HUSSERL, Edmund. Meditações Cartesianas, Conferências de Paris. Trad. de Pedro M. S. Alves. Lisboa: Phainomenon - Clássicos de Fenomenologia, 2010.

JASPERS, Karl. Introdução ao pensamento filosófico. Trad. de. São Paulo: Cultrix, 1976.

KAKUTANI, Michiko. A morte da verdade. Trad. de André Czarnobai e Marcela Duarte. Rio de Janeiro: Intrínseca, 2018.

KANT, Immanuel. Resposta à pergunta: “Que é o Iluminismo?” Trad. de Artur Mourão. Lisboa: Ediçoes 70, 1980.

LARA, Tiago Adão. Caminhos da razão no Ocidente. 2. ed. Petrópolis: Vozes, 1986.

LIMA VAZ, Henrique Cláudio de. A filosofia do Brasil, hoje. Cadernos da SEAF. Belo Horizonte: 1978. v. 1.

LUCHESI, Cipriano Carlos; PASSOS, Elizete Silva. Introdução à filosofia: aprendendo a pensar. 4. ed. São Paulo: Cortez, 2002.

LUCHESI, Cipriano Carlos. Fazer Universidade: uma proposta metodológica. São Paulo: Cortez, 1984.

MORAIS, Pessoa de. O Desafio da Era Tecnológica. Rio de Janeiro: Civilização Brasileira, 1971,

NAGEL, Ernest. Ciência: natureza e objetivo. In: MORGENBESSER, Sidney. Filosofia da Ciência. São Paulo: Cultrix, 1985, p. 16.

OLIVEIRA, Manfredo Araújo de. A ontologia em debate no pensamento contemporâneo. São Paulo: Paulus, 2014.

PUNTEL, L.B. Metaphysics: a traditional mainstay of philosophy in need of radical rethinking. In: Review of Metaphysics. New York: 2011.

RICOUER, Paul. História e Verdade. Trad, de F.A. Ribeiro. Rio de Janeiro: Forense, 1968.

SÁ MARTINO, Luís Mauro. Em busca de uma região desconhecida: introdução à filosofia concreta. In: SANTOS, Mário Ferreira dos. Filosofia Concreta. São Paulo: É Realizações, 2009.

\begin{tabular}{|c|c|c|c|c|}
\hline Qenista Dialectus & Ano 9 & n. 19 & Agosto - Dezembro 2020 & p. $114-134$ \\
\hline
\end{tabular}


SANTOS, Mário Ferreira dos. Filosofia Concreta. São Paulo: É Realizações, 2009. 